\title{
Interculturalidade e a conjunção de saberes que congregam a atenção em saúde
}

Marcia Mocellin Raymundo

\begin{abstract}
Resumo
O artigo objetiva discutir a atenção em saúde sob uma perspectiva intercultural e laica. A proposição da bioética como interdisciplina, desde Potter até autores contemporâneos, traz consigo forte estímulo à reflexão sobre a atenção em saúde e a premente necessidade de diálogo entre os saberes envolvidos nesta área. A interculturalidade, como proposta de abordagem em saúde, remete ao pensamento de que não é possível exercer a atenção em saúde sem relacioná-la com outros elementos envolvidos além dos biológicos, tais como históricos, sociais, políticos, econômicos, religiosos, culturais, entre outros. Um modelo de atenção em saúde pode ser construído a partir da interpretação de uma realidade, que por sua vez também pode ser construída. Atualmente, os distintos modelos de atenção em saúde existentes se deparam com o desafio de integrar-se entre si, com base em seus saberes diversos, legitimando uma real atenção integral em saúde.

Palavras-chave: Serviços de saúde. Assistência à saúde. Diversidade cultural.
\end{abstract}

\section{Resumen}

\section{Interculturalidad, y la conjunción de saberes que conforman la atención en salud}

El objetivo de este trabajo es discutir la salud desde una perspectiva intercultural y laica. La propuesta de la bioética como interdisciplinaria, desde Potter hacia los autores contemporáneos, aporta un fuerte estímulo a la reflexión sobre el cuidado en salud y la urgente necesidad de un diálogo entre los saberes involucrados en este campo. La interculturalidad, como una propuesta de enfoque en salud, nos lleva a la idea de que no es posible ejercer el cuidado en salud sin relacionarlo con otros elementos que intervienen más allá de lo biológico, tales como el histórico, social, cultural, político, económico, religioso, entre otros. Un modelo de atención en salud se puede construir a partir de la interpretación de una realidad, que a su vez, se puede también construir. En la actualidad, los distintos modelos de atención existentes en salud se enfrentan con el desafío de integrarse unos con los otros, basados en sus saberes diversos, legitimando una real atención integrada en salud.

Palabras-clave: Servicios de salud. Prestación de atención de salud. Diversidad cultural.

\section{Abstract \\ Interculturality and the conjunction of knowledge that gathers health care}

The paper aims to debate health care from an intercultural and secular perspective. The proposition of bioethics as interdisciplinary, from Potter to contemporary authors, brings a strong incentive to reflection on health care and the urgent need for dialogue between the knowledge involved in this area. Interculturality, as a possible approach in health, leads to the thinking that it is not possible to exercise the health care without relating it to other elements beyond the biological, such as historical, social, political, economic, religious, cultural, among others. A health care model can be constructed from the interpretation of a reality, which in turn, can also be constructed. Currently, the different health care models face the challenge of integrating with each other, based in the different knowledge, legitimizing an integral health care attention.

Key words: Health services. Delivery of health care. Cultural diversity.

Doutora marciamocellin@gmail.com - Universidade Federal do Rio Grande do Sul (UFRGS)/Hospital de Clínicas de Porto Alegre, Porto Alegre/RS, Brasil.

Correspondência

Hospital de Clínicas de Porto Alegre - Rua Ramiro Barcelos, 2.350, Sala 2227, Bom Fim CEP 90035-903. Porto Alegre/RS, Brasil.

Declara não haver conflito de interesse. 
O presente artigo, de caráter ensaístico, propõe a reflexão sobre a necessidade de consideração de aspectos relativos à interculturalidade na atenção em saúde. Portanto, quando mencionamos a atenção em saúde nos referimos ao conjunto organizado - dentro de um sistema - de políticas que visam atender as demandas de cuidados de saúde dos indivíduos que, diversamente, compõem a sociedade. Esta política, mediante diferentes estratégias de ação, tais como programas e planos, norteará as práticas que resultarão na atenção em saúde.

As práticas de saúde, por conseguinte, podem ser entendidas como o conjunto de saberes utilizados para reconhecer ou identificar um problema relacionado ao equilíbrio físico e/ou mental de uma pessoa, e, consequentemente, planejar ações que visam recuperar este equilíbrio. Tanto as práticas quanto à atenção em saúde são fortemente influenciadas por processos culturais, históricos, sociais, políticos e econômicos. Além desses fatores, existem outros, de caráter mais subjetivo, que também influenciam as práticas de saúde: as crenças e a religião.

Todos estes componentes fazem com que a atenção em saúde se constitua por processos dinâmicos, constantemente sujeitos a revisões e reconfigurações. Adicionalmente, as práticas se concretizam a partir de distintos modelos, sendo que alguns deles se sobrepõem a outros, tornando-se dominantes, como no caso do modelo biomédico científico. Contudo, a partir da popularização e da própria demanda de usuários por práticas alternativas de atenção em saúde, surgem novas possibilidades de modelo de atenção - inclusive, o próprio modelo biomédico inicia paulatinamente um processo de mescla entre saberes científicos e saberes alternativos. Trata-se de uma nova configuração de atenção em saúde, que surge focada não somente nos aspectos biológicos, mas também nos demais aspectos que influenciam o bem-estar dos indivíduos, tais como socioculturais, espirituais, econômicos, entre outros.

Atualmente, não há espaço para reducionismos, nem biológicos, nem socioculturais. $E$, se há algum tempo estes se configuravam isoladamente e com mínimo diálogo, pouco a pouco estão sendo reconfigurados a partir do intercâmbio e da interdisciplinaridade. No campo da atenção em saúde não é diferente, e novos espaços de diálogo surgem, integrando saberes de origem científica com aqueles chamados tradicionais. Essa mescla favorece as inter-relações e a complementaridade, resultando em consequentes processos interculturais.

Entretanto, cabe lembrar que a presença do diálogo não necessariamente significa ausência de conflitos, e é a partir de ambos, diálogo e conflito, que se consolida o papel mediador da interculturalidade. Pois, como aponta Gil, se o contato com o diferente é uma inevitabilidade do processo cultural e se o conflito - comunicativo e não comunicativo -, tal como o diálogo, constitui um componente essencial deste momento, a interculturalidade erige-se como estratégia fundamental de mediação. Todavia, seria utópico conceber a interculturalidade como um processo inevitavelmente com sucesso, como uma espécie de solução mágica que supera a violência manifesta, sempre que a identidade cultural está em jogo. A interculturalidade e seus múltiplos avatares jogam no campo da mediação do diferente, mas de forma alguma em campo neutro ${ }^{1}$.

Por sua vez, este diálogo se dá não somente entre culturas e identidades distintas, mas também entre diferentes saberes e campos do conhecimento, ou até mesmo entre distintas lógicas institucionais, como a lógica de mercado e a lógica do Estado, por exemplo. Neste contexto, pode-se considerar a interculturalidade em saúde como a complementaridade entre diferentes visões sobre uma mesma questão de saúde, que se estabelece a partir do diálogo e do intercâmbio. Trata-se da coexistência de distintas cosmovisões de maneira complementar, sem preconceitos ou imposição de uma sobre outra ${ }^{2}$. 0 enfoque da atenção em saúde passa a ser não apenas biológico, não apenas sociocultural, mas biocultural ou, ainda melhor, biopsicossociocultural.

Esta síntese de aspectos refletirá a pessoa em seu todo, não apenas a parte na qual se apresenta o ponto em desequilíbrio de sua saúde. Tanto as ciências biomédicas quanto as psicossociais passaram a utilizar estas abordagens interdisciplinares, incrementando a qualidade da atenção. O avanço no campo do tratamento de algumas doenças na área da saúde mental é exemplo, no qual achados recentes propõem que pode também existir relação da doença com alterações sistêmicas ${ }^{3}$.

O impacto destes avanços pode levar ao desenvolvimento de medicamentos mais efetivos. Paralelamente, as ciências biomédicas também se utilizam de conhecimentos e práticas tradicionais, agregando-as no tratamento de algumas doenças ou sintomas. A recente introdução de práticas integrativas em várias especialidades exemplifica esta complementaridade. A prática de yoga, por exemplo, tem se destacado por apresentar resultados eficientes em diversos agravos à saúde, incluindo desde o alívio de sintomas do climatério até a redução dos níveis de pressão sanguínea. Em recente metanálise que avaliou 17 estudos envolvendo pacientes 
hipertensos e pré-hipertensos, a prática de yoga demonstrou modesto, porém significante, efeito sobre a pressão sanguínea. Os resultados sugeriram que a yoga pode ser oferecida como intervenção complementar efetiva na redução da pressão sanguínea de pessoas hipertensas e pré-hipertensas ${ }^{4}$. Importante lembrar que estas práticas integrativas têm sido agregadas a tratamentos convencionais no sentido de somar, não de substituir, refletindo precisamente o diálogo entre os diferentes saberes e a possibilidade de complementaridade.

Esta absorção de práticas integrativas por modelos biomédicos de cunho predominantemente científico ilustra a realidade já vivenciada pelos próprios pacientes, que percorrem distintas trajetórias em busca de atenção e, frequentemente, incluem alternativas terapêuticas. Para o paciente, não necessariamente será o método utilizado o mais importante em seu processo de atenção, mas o resultado alcançado, baseado, além dos aspectos científicos, neste outro amplo espectro de componentes que influenciam e configuram sua pessoa. Portanto, é por meio do diálogo com o paciente que se construirão os sentidos de cada processo ou sistema de atenção.

Além do pertencimento sociocultural de cada pessoa, suas crenças e valores também influenciarão na construção dos seus significantes e significados em saúde. De acordo com estas afiliações, o paciente definirá os rumos que buscará para seu processo de atenção em saúde, desde os primários até os mais sofisticados. E, ainda, além das crenças existem outros fatores que poderão influenciar este processo, tais como as explicações baseadas em outras significações, como, por exemplo, atribuir um determinado temperamento a cor do cabelo, a estatura, ao signo zodiacal, entre outros. Importante lembrar que os profissionais de saúde também possuem suas crenças e valores, mas, muitas vezes, embora o esperado é que a atenção em saúde ocorra de maneira imparcial, estas crenças e valores se sobrepõem e, não raro, ocorre conflito entre profissional e paciente, por conta destas afiliações e pertencimentos.

Os aspectos anteriormente explicitados nos permitem inferir que alguns conflitos identificados na atenção em saúde surgem também a partir de barreiras culturais, quando profissionais e pacientes discordam sobre os significados atribuídos a uma mesma ação ou prática. Nos deparamos com algumas situações em que cada um defende sua interpretação ou sua forma de viver e atuar no mundo, classificando-a como a única correta. Contudo, a partir das diferenças é que devemos estabelecer esta ética de inter-relações, nas quais as distintas visões são respeitadas, porém, sem imposição ao outro.

As construções simbólicas e interpretativas em torno das questões de saúde ultrapassam os aspectos biológicos e se configuram contextualmente. Assim, trata-se basicamente de integrar a objetividade das ciências biomédicas, que aportam explicações sobre o funcionamento e as atividades do corpo humano, com a subjetividade referenciada pela corporalidade, que vai além dos aspectos anatômicos e fisiológicos. Lembrando que, como afirma DuránAmavizca, o ser humano, antes de ser humanamente homem, é corpo, posteriormente o homem atua como sujeito. Sendo que o termo homem, aqui, refere-se à categoria filosófica.

Para a autora, a subjetividade do homem se desenvolve a partir de significações, mas tal subjetividade não pode prescindir de um corpo. Por sua vez, este corpo e esta subjetividade não poderão prescindir do ser humano que possui o corpo, com seus órgãos e suas emoções, em sua trajetória como ser social, cultural e dotado de linguagem, com as quais conforma a sua identidade ${ }^{5}$. É justamente este ser social e cultural, dotado de linguagem e de uma série de particularidades, que se configura no usuário dos sistemas de saúde e que busca pela atenção trazendo em sua bagagem o pertencimento a grupos, sociedades, culturas, classes sociais e demais tipos possíveis de agregações em torno de um mínimo comum.

Questiona-se, então, sobre como se estabelece de fato esta relação com o corpo e seus significados a partir da diversidade cultural que existe em um cenário de atenção em saúde. Por muito tempo a atenção em saúde foi exercida partindo do pressuposto de que as pessoas possuíam características comuns que a tornavam homogêneas, e que as questões de saúde poderiam ser abordadas igualmente, partindo das categorizações que preestabeleciam o comportamento, os sintomas, as atitudes e outros atributos que configuravam o pertencimento a esta categoria. Uma espécie de "pasteurização" do ser humano, tomando como parâmetro as características das categorias hegemônicas.

Exemplifica essa ideia a proposta que vigorou ao longo de muitos anos, que seguia a tendência de atender todas as mulheres, quanto aos aspectos ginecológicos, da mesma maneira, ou seja, aplicandose o mesmo protocolo de atendimento, sem considerar questões particulares a elas. Embora todas pertençam a um mesmo gênero, e isso é comum, existem muitas outras particularidades dentre 0 grupo formado pelo gênero mulher. As particulari- 
dades das mulheres orientais não são as mesmas das mulheres ocidentais, e ainda, dentre as ocidentais devemos considerar que existem particularidades entre as europeias, as africanas e as latinas, apenas para citar alguns exemplos. Mas, também devemos reconhecer que dentre todas as latinas existem ainda outras particularidades. As latinas de origem indígena possuem características que não são encontradas nas latinas não indígenas, e assim podemos citar inúmeros exemplos de particularidades de grupos conformados por vários fatores, não somente os étnicos. Estas considerações justificam que a atenção em saúde seja conformada com base em uma série de fatores, que resultarão, por sua vez, na atenção particularizada a cada grupo - porém sem perder o foco comum da atenção.

Na prática, as situações de atendimento podem se apresentar com maior ou menor grau de complexidade desde o ponto de vista das questões particulares a cada grupo, mas, por exemplo, quando uma mulher de origem cigana procura por atendimento ginecológico, seria razoável que sua cultura fosse respeitada e que esse atendimento fosse proporcionado por uma profissional mulher, de acordo com os significados para este grupo. $O$ que pode parecer curioso ou sem importância para uma cultura, pode não ser para outra. E estas barreiras culturais podem ser vencidas a partir do diálogo com o paciente, pois é a partir dele que se constroem os sentidos.

Conforme mencionado, as barreiras culturais levam muitas vezes a que uma pessoa pense que sua forma de viver é a única autêntica, mas há que reconhecer o direito do outro. Em paralelo, tampouco faz sentido questionar por que razão procuram os serviços de saúde, quando não operam dentro desta lógica dominante. Todavia, se vivemos em sociedades plurais, deveríamos também implementar lógicas plurais de atenção, sempre insistindo que não se trata de relativizar os protocolos de atenção, mas as abordagens de atenção. Ou seja, não se trata de cada instituição de saúde desenvolver um protocolo específico de atendimento para cada diferente paciente, de acordo com suas particularidades. Mas precisamente de considerar a pluralidade da atenção e oferecer distintas possibilidades de atendimento. Exemplo disso são alguns hospitais na Bolívia, que oferecem a possibilidade de realização de parto tanto no modelo médico científico quanto no modelo de parto intercultural, de acordo com as tradições dos povos originários. A escolha do modelo de parto desejado é realizada pela própria paciente e seus familiares, sendo que as equipes de atenção, tanto de parto intercultural quanto convencional, permanecem à disposição para o atendimento ${ }^{6}$.

No imaginário de muitas pessoas existe um simbolismo que leva a crer que grupos pertencentes a etnias não dominantes, ou que possuem sistemas de cura próprios, como os indígenas, por exemplo, não desejariam receber atenção em saúde baseada em modelos biomédicos. Contudo, verifica-se que na prática, assim como existe um trânsito das pessoas pertencentes a classes sociais hegemônicas, que buscam tanto o modelo biomédico científico quanto as alternativas terapêuticas, as pessoas que pertencem a outras classes não dominantes também utilizam seus sistemas de cura, mas buscam, quando necessário, os sistemas de saúde baseados no modelo científico. Esta transitoriedade entre os diferentes modelos configura também a interculturalidade em saúde.

Porém, este cenário de complementaridade nem sempre se caracteriza por um caminho livre de tensões e controvérsias entre os diferentes grupos que defendem, cada qual, sua prática ou modelo de atenção. $\mathrm{O}$ modelo biomédico científico está referenciado em evidências científicas, e emprega práticas sistematicamente fiscalizadas por colegiados e órgãos governamentais ou autarquias. Paralelamente, as práticas integrativas possuem trajetos distintos para sua aplicação, que não necessariamente são acompanhadas por algum sistema regulatório, e, por vezes, os praticantes embasam suas atividades mais em suas próprias habilidades e conhecimentos adquiridos do que em formações profissionalizantes. É o caso, por exemplo, de curandeiros, benzedeiros e outras modalidades de terapeutas alternativos. A crescente utilização de tais práticas, associada ao seu resgate por outros grupos, tem levado a discussão e, inclusive, à busca de uma regulamentação que as legitimem.

\section{Categorias e identidades}

Para melhor compreender como se configura a territorialidade ou os limites de alguns espaços na área da saúde, devemos adentrar em um campo ainda mais complexo: o das identidades. Frequentemente, a abordagem em saúde ocorre a partir das características dos grupos, partindo de uma homogenização das características que seriam comuns, porém, não raro, desconsiderando o relevante papel exercido pelas identidades.

Efetivamente, trata-se de perceber as identidades como relacionais, enquanto a diferença é estabelecida por uma marcação simbólica, relativa- 
mente a outras identidades. No campo prático, isto também significa que algumas vezes as identidades são tomadas como fixas e imutáveis, e reivindicações essencialistas são assumidas visando determinar quem pertence e quem não pertence a determinado grupo identitário ${ }^{7}$. Ou seja, vivemos em meio a categorizações resultantes das representações simbólicas que definirão a identidade.

Assim, a identidade existe porque existe algo que não pertence a ela. Existimos a partir do outro e nos definimos como queremos nos definir. Nos associamos a uma imagem, a uma caracterização, mas a categoria é definida a partir de variados fatores, inclusive socioeconômicos. As categorias hegemônicas definem as outras categorias, e as relações se estabelecem a partir da aceitação da categoria. De acordo com Jiménez-Silva, a especificidade do ser humano não passa somente pela autoconsciência de si, senão pela autoconsciência mediada pela consciência do outro, do semelhante ${ }^{8}$, mediada também, e principalmente, pela consciência do diferente, que são, em última análise, aqueles que configuram o limite identitário do nós. Existimos porque existe o outro, e é por meio das relações cotidianas e dos intercâmbios que se estabelecem as identidades e os processos simbólicos que configuram a sociedade.

De acordo com Tadeu da Silva, sabemos que a identidade e a diferença são o resultado de um processo de produção simbólica e discursiva. A identidade, tal como a diferença, é uma relação social. Elas não são simplesmente definidas, são impostas, e não convivem harmoniosamente, lado a lado, em um campo sem hierarquias, são disputadas. A identidade e a diferença estão, pois, em estreita conexão com as relações de poder ${ }^{9}$.

Conforme aponta Gutiérrez-Martínez, desde seu início o termo identidade havia sido definido como um processo que se constrói dia a dia, mediante apreensão de identificações específicas. Para o autor, embora a noção de identidade já houvesse sido descrita como um processo constante, contínuo, móbil, aberto em seu entorno social e contextualizado, instaurou-se uma noção de identidade estática, fixa, fechada, com traços essencialistas, de permanência e totalidade ${ }^{10}$.

A compreensão dos processos identitários no campo da saúde é de suma importância, haja vista influenciar diretamente os processos relacionais, sobretudo entre profissionais de saúde e pacientes. Contudo, por vezes, se percebe uma sobrevalia das características essencialistas, como fatores biológicos ou étnicos, por exemplo. Com muita frequência, o campo da sexualidade é tratado desta forma, com tal rigidez e alto grau classificatório que os verdadeiros matizes existentes entre as categorias prédeterminadas se veem obscurecidos ou peremptoriamente negados.

Sendo assim, existem elementos transculturais que devem ser considerados. Nenhuma cultura nega a existência do corpo, mas a sexualidade e as práticas sexuais não são universais e as pessoas estão constantemente reinventando sua sexualidade, sua identidade sexual. Portanto, a sexualidade deveria ser considerada não tomando por base a norma, mas considerando a construção a partir das próprias pessoas.

É necessário repensar estas categorizações pétreas, permitindo que os processos identitários se legitimem a partir dos sentimentos de pertencimento, e não do estabelecido a partir das categorias dominantes, por vezes responsáveis, inclusive, pela demarcação das fronteiras do corpo. A criação das categorias parte muitas vezes de estereótipos. Determinadas características corporais emolduram imagens que demarcam as fronteiras do corpo.

Assim, cor da pele, tipo de cabelo, conformação corporal e facial permitem conhecer imagens culturais. E muitas vezes um estereótipo dita o comportamento que é seguido por uma identificação aprendida, ou seja, adquirida a partir das interações cotidianas, por fazer parte de uma sociedade. Paralelamente, em algumas situações se aprende a construir novas noções de identidade para sobreviver à dominação, resultando em (re)significações ou novas representações coletivas. Para alguns autores, as identidades, como ferramenta de reflexão, se converteram em instrumento concreto para compreender a atividade cotidiana e complexa dos seres humanos em constante interação ${ }^{11}$.

Historicamente, estas atribuições baseadas em características biológicas fundamentaram ações discriminatórias e exploratórias, inclusive a construção de uma categorização da sociedade nas chamadas "raças". Porém, como bem afirma Pena, os avanços da genética molecular e o sequenciamento do genoma humano permitiram o exame detalhado da correlação entre a variação genômica, a ancestralidade biogeográfica e a aparência física das pessoas, mostrando como os rótulos antes usados para distinguir "raças" não têm significado biológico. É fácil distinguir fenotipicamente um europeu de um africano ou de um asiático, mas tal facilidade desaparece completamente quando procuramos evidências dessas diferenças "raciais" nos respectivos genomas.

Diante desta evidência se deve fazer todo o esforço em prol de uma sociedade desracializada, 
que valorize e cultive a singularidade do indivíduo e na qual cada um tenha a liberdade de assumir, por escolha pessoal, uma pluralidade de identidades, em vez de um rótulo único, imposto pela coletividade. Para o autor, o racismo não decorreu da invenção das raças, ele a precedeu, e a única divisão biologicamente coerente da espécie humana seria a realizável em seis bilhões de indivíduos, cada um deles singular em seu genoma e história de vida ${ }^{12}$. As sábias palavras de Sérgio Pena estimulam a que pensemos cada vez mais sobre como esta categoria inventada serviu, e segue servindo, para impor distanciamentos ilusórios e fictícios, levando à discriminação.

Curiosamente, a apropriação de um argumento baseado em aspectos biológicos foi utilizada para justificar a discriminação, por meio da construção da categoria "raça", mas, é justamente a partir do avanço do conhecimento genômico que também um argumento biológico permite defender a inexistência das raças. Este é um exemplo ímpar de aplicação do conhecimento científico em prol do bem comum da sociedade. Resta-nos disseminar este importante conhecimento, e aplicá-lo na prática.

Neste sentido, constata-se que existe a preocupação do meio acadêmico em prover informações pertinentes e adequadas sobre as questões étnicas e sua implicação no campo da saúde. Em recente artigo publicado no European Journal of Public Health foram propostos princípios-chave para a realização de pesquisas sobre etnia e saúde, justamente pela consideração de que há evidências substanciais de que as experiências de saúde e de cuidados de saúde variam de acordo com características étnicas. Entender essas experiências se faz necessário para combater as desigualdades étnicas no campo da saúde ${ }^{13}$.

\section{Diversidade, cultura e saberes}

Todos conformamos a diversidade, mas, frequentemente, quando falamos em diversidade pensamos no diferente, sem nos darmos conta de que também podemos ser o diferente para o outro. A diversidade é composta pela variabilidade, por isso a conformamos todos. A sociedade e suas exigências normativas levam a categorizações e polarizações.

No campo da saúde esta polarização se apresenta, inclusive, nos discursos, construídos a partir das interpretações. A experiência da doença (padecer) será sempre determinada culturalmente, ou seja, a partir das relações culturais. O reconhe- cimento do significado desta experiência é uma interpretação a partir da bagagem de cada um. 0 paciente perceberá a doença e construirá interpretações a partir de experiências não limitadas à doença ${ }^{14}$. Já os profissionais manejam seu próprio modelo explicativo a partir dos conceitos conhecidos e seus significados, de seus conhecimentos e modelo construído.

Em seu livro Ticiotl, Viesca-Treviño nos brinda com uma viagem ao passado e um profundo estudo dos conceitos médicos dos antigos mexicanos, abordando a história da medicina pré-hispânica, e sua negação com a chegada dos espanhóis. O autor mostra de maneira irreparável, por meio das narrativas registradas pelos próprios autores espanhóis, tais como Nicolas Monardes, Francisco Hernández, Fray Bernardino de Sahagún, entre outros, como o conhecimento dos curadores indígenas, e consequentemente sua medicina, foi categoricamente desqualificado como entidade existente.

Como exemplo, relata que enquanto Monardes pedia que fossem aos mercados perguntar aos indígenas sobre sua maravilhosa medicina e seu uso, buscando dar continuidade aos seus conhecimentos médicos com os saberes da medicina indígena, Hernández, dez anos depois, negava totalmente esta última, identificando-a como inepta e ignorante. Em seu entender, não se podia perguntar aos médicos nativos quais eram seus medicamentos e para que serviam, mas era indispensável reinterpretá-los e reclassificá-los segundo os padrões galênicos, vigentes à época.

Com isso, a medicina indígena, seus conceitos, seu acervo de conhecimento, suas bases de crenças, foram declarados inexistentes, deixaram de ser vistos como um saber para passar a ser uma ignorância. As verdades e conhecimentos parecem ser relativos e válidos somente para a pessoa que os criou e para aquele cujos filtros culturais o permitam apropriar-se deles e assumir seu significado. Os conquistadores e primeiros povoadores europeus da Nova Espanha não imaginavam sequer que poderia existir outra medicina diferente daquela que se exercia na Europa ${ }^{15}$.

O exemplo anterior ilustra claramente a maneira como o poder das categorias hegemônicas também determina quais saberes serão considerados válidos. Ou seja, o modelo biomédico vigente historicamente perpassa as relações de poder e outorga validade a determinadas práticas, elegíveis como legítimas. Para aquelas que não forem condizentes, resta a desqualificação, a negação e o esquecimento. 
Portanto, não se pode refletir sobre os vários saberes sem considerar o contexto e as relações de poder. A interculturalidade busca promover o diálogo contextualizado, a partir das experiências de cada interlocutor, intentando a comunicação efetiva, não apenas superficial. Para tal, existem fatores que contribuem para a comunicação intercultural, em seu amplo sentido, tais como conhecer a cultura do outro, reconhecer a própria cultura, eliminar ou neutralizar preconceitos, ser capaz de estabelecer relações empáticas e saber reconhecer a metacomunicação: aquela não evidente.

Adicionalmente, existem fatores que dificultam a comunicação intercultural, como a ignorância, a universalização a partir de conceitos próprios e a supervalorização das diferenças ${ }^{16}$. A contextualização se torna imprescindível quando abordamos temas relacionados à saúde, sobretudo se examinamos historicamente como surgem e se estabelecem novas doenças. No caso de países colonizados, por exemplo, são facilmente identificáveis os processos epidêmicos introduzidos a partir do intercâmbio biológico e cultural entre civilizações de origens étnicas distintas. A história do processo biológico, e também da evolução das doenças, não ocorre isolada do contexto social e cultural, em cujo espaço e tempo surge, cresce e amadurece ${ }^{17}$. Portanto, também é preciso reconhecer que a medicina tradicional ou alternativa responde a diferentes momentos históricos, o que provavelmente não foi considerado por Hernández, quando da desqualificação dos saberes pré-hispânicos.

Atualmente, é realidade inegável em grande parte das sociedades humanas a existência de modos diversos de entender a saúde e a doença, de diagnosticar e tratar. Essa variedade é chamada de pluralismo médico, terapêutico ou assistencial. Em quase todos os grupos humanos existem diversas instâncias assistenciais e terapêuticas que podem ser utilizadas por seus membros para resolver seus problemas de saúde. A definição e valoração dos próprios problemas de saúde e sua relação com o contexto social, econômico, político e cultural pode ser compreendida no âmbito do estudo do pluralismo assistencial ${ }^{18}$.

Diante da constatação da pluralidade social, assim como da diversidade cultural, se faz necessário considerar este pluralismo para promover o diálogo entre os diferentes saberes, vez que o objetivo comum entre amboséjustamente buscar o equilíbrio ou o estado de saúde por meio da atenção. E se existem diferentes caminhos para chegar a esta atenção, não há que negá-los, mas sim partilhá-los.

As relações entre a sociedade e a prática médica sempre existiram em todas as épocas da humanidade. A forma como tais vínculos se materializaram está sujeita ao entorno que tiveram em cada época, tanto a sociedade como a medicina ${ }^{19}$. Compete aos atores envolvidos no campo destes saberes implicados na atenção em saúde promover a interculturalidade, pois esta implica em que os diferentes se encontrem em um mesmo mundo e convivam em relações de negociação e empréstimos recíprocos ${ }^{20}$.

\section{Considerações finais}

A reflexão proposta neste artigo visou alertar para a importância da consideração da pluralidade de formas assistenciais e de atenção em saúde, de acordo com diferentes visões e interpretações, dentro da perspectiva de interdisciplinaridade. Quando Potter propôs a bioética como nova ciência ética que combina humildade, responsabilidade e uma competência interdisciplinar e intercultural que potencializa o sentido de humanidade, certamente não se tratava de pura retórica, mas de apelo à consideração desta pluralidade e a verdadeira conjunção entre as ciências e as humanidades ${ }^{21}$.

Esta contribuição no sentido de chamar a atenção para a importância da conjunção dos saberes, por vezes, é esquecida ou tomada como menos importante do que o próprio avanço do conhecimento científico. Porém, mesmo o avanço do conhecimento está inserido em um contexto histórico, social, cultural, econômico, entre outros, que o influenciarão. E, se tomada em conta esta contextualização, certamente o processo será mais profícuo.

No atual contexto, e de acordo com a tendência de integração entre os saberes, é imprescindível estimular que os profissionais envolvidos na atenção em saúde e na produção do conhecimento neste campo considerem esta pluralidade e percebam que a diversidade vem para somar - e não para segregar. O modo de fazer ciência descontextualizada e sem intercâmbio com outras áreas passa a ser um modelo ultrapassado, com aplicabilidade limitada. Nesse sentido, a interculturalidade em saúde possui relevante papel, podendo favorecer não somente a integração dos saberes, como também uma justificativa teórico-prática para implementar novas visões a partir de antigos saberes. 


\section{Referências}

1. Gil IC. As interculturalidades da multiculturalidade. In: Lages MF, Matos AT, coordenadores. Portugal: percursos de interculturalidade. Lisboa: Acidi; 2008. p. 30-48.

2. Raymundo MM. Uma aproximação entre bioética e interculturalidade em saúde a partir da diversidade. Revista HCPA. 2011;31(4):491-6.

3. Magalhães PVS, Fries GR, Kapczinski F. Marcadores periféricos e a fisiopatologia do transtorno bipolar. Rev Psiquiatr Clin. 2012;39(2):60-7.

4. Hagins $M$, States R, Selfe T, Innes K. Effectiveness of yoga for hypertension: systematic review and meta-analysis. Evidence Based Complementary Alternative Medicine. 2013;(2013). p. 13.

5. Amavizca NDD. Introducción. In: Amavizca NDD, Silva MPJ, Pilar M del., coordinadores. Cuerpo, sujeto e identidad. Ciudad de México: Universidad Nacional Autónoma de México/Instituto de Investigaciones sobre la Universidad y la Educación/Plaza y Valdés Editores; 2009. p. 171-85.

6. Escudero C. Bolívia: los partos interculturales son inclusivos con respecto a las poblaciones indígenas, ancestralmente las más desfavorecidas. [Internet]. AmecoPress. Bolívia; 2011 [acesso 8 jun. 2013]. Disponível: http://www.amecopress.net/spip.php?article8372

7. Woodward K. Identidade e diferença: uma introdução teórica e conceitual. In: Silva TT, organizador. Identidade e diferença: a perspectiva dos estudos culturais. $8^{\mathrm{a}}$ ed. Petrópolis: Vozes; 2008. p. 7-72.

8. Silva MPJ. Sujeto e identidad. In: Amavizca NDD, Silva MPJ, Pilar M del., coordinadores. Cuerpo, sujeto e identidad. Ciudad de México: Universidad Nacional Autónoma de México/Instituto de Investigaciones sobre la Universidad y la Educación/Plaza y Valdés Editores; 2009. p. 171-85.

9. Silva TT. A produção social da identidade e da diferença. In: Silva TT, organizador. Identidade e diferença: a perspectiva dos estudos culturais. Petrópolis: Vozes; 2000. p. 73-102.

10. Martínez DG. Ciências del outro, pluralidades culturales y políticas. In: Martínez DG, Bodek C, coordinadores. Identidades colectivas y diversidad. Ciudad de México: Universidad Nacional Autónoma de México; 2010. p. 31-57.

11. Martínez DG. A manera de introducción: hacia una dinámica de los umbrales de las identidades. In: Martínez DG, coordenador. Epistemología de las identidades. Ciudad de México: Universidad Nacional Autónoma de México; 2010. p. 11-39.

12. Pena SDJ. Humanidade sem raças? São Paulo: Publifolha; 2008, p. 72.

13. Mir G, Salway S, Kai J, Karlsen S, Bhopal R, Ellison GT et al. Principles for research on ethnicity and health: the leeds consensus statement. Eur J Public Health. 2013;23(3):504-10.

14. Vargas LA, Cortés FM. Una mirada antropológica a la enfermedad y el padecer. Gac Med Mex. 1991;127(1):3-6.

15. Treviño CV. Ticiotl: conceptos médicos de los antiguos mexicanos. Ciudad de México: Unam; 1997.

16. Navarro SG, Armeijach MJ, Costa XC. Interculturalidad y salud. Barcelona: Viguera; 2010.

17. Beltrán GA. Antropología médica. Ciudad de México: Fondo de Cultura Económica; 1994.

18. Perdiguero E. Una reflexión sobre el pluralismo médico. In: Juárez GF, coordinador. Salud e interculturalidad en América Latina: antropología de la salud y crítica intercultural. Quito: AbyaYala; 2006. p. 33-49.

19. Gante SR. Concepto histórico-social de la enfermedad. In: Cortés-Riveroll JGR, Pérez-González D, Gante SR, Briones-Rojas R, coordinadores. Nociones históricas sobre la enfermedad. Puebla: Benemérita Universidad Autónoma de Puebla; 2008.p. 259-93.

20. Canclini NG. De la diversidad a la interculturalidad. In: Canclini NG, coordinador. Conflitos interculturales. Barcelona: Gedisa;2011.p.102-12.

21. Potter VH. Bioética global. Revista O Mundo da Saúde. 1998; 22(6):370-4.

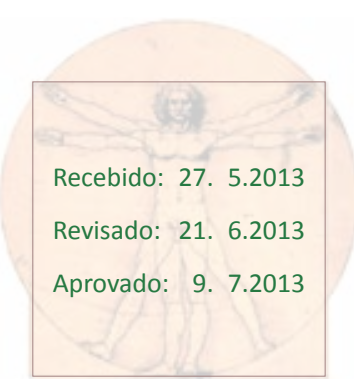

